\title{
PERANAN AIR TRAFFIC CONTROL UNTUK KESELAMATAN PENERBANGAN DI INDONESIA
}

\section{Primadi Candra Susanto ${ }^{1}$, Prasadja Ricardianto ${ }^{2}$, Hartono ${ }^{3}$, Ryan Firdiansyah ${ }^{4}$ \\ 1,2 Institut Transportasi dan Logistik TRISAKTI, Jakarta, Indonesia \\ ${ }^{3}$ Puslitbang Transportasi Jalan dan Perkeretaapian, Jakarta, Indonesia ${ }^{4}$ Sekolah Tinggi Penerbangan Aviasi, Jakarta, Indonesia}

e-mail: primstrisakti@gmail.com, ricardianto@gmail.com, ambonharto@gmail.com, ryan.firdiansyah.1979@gmail.com

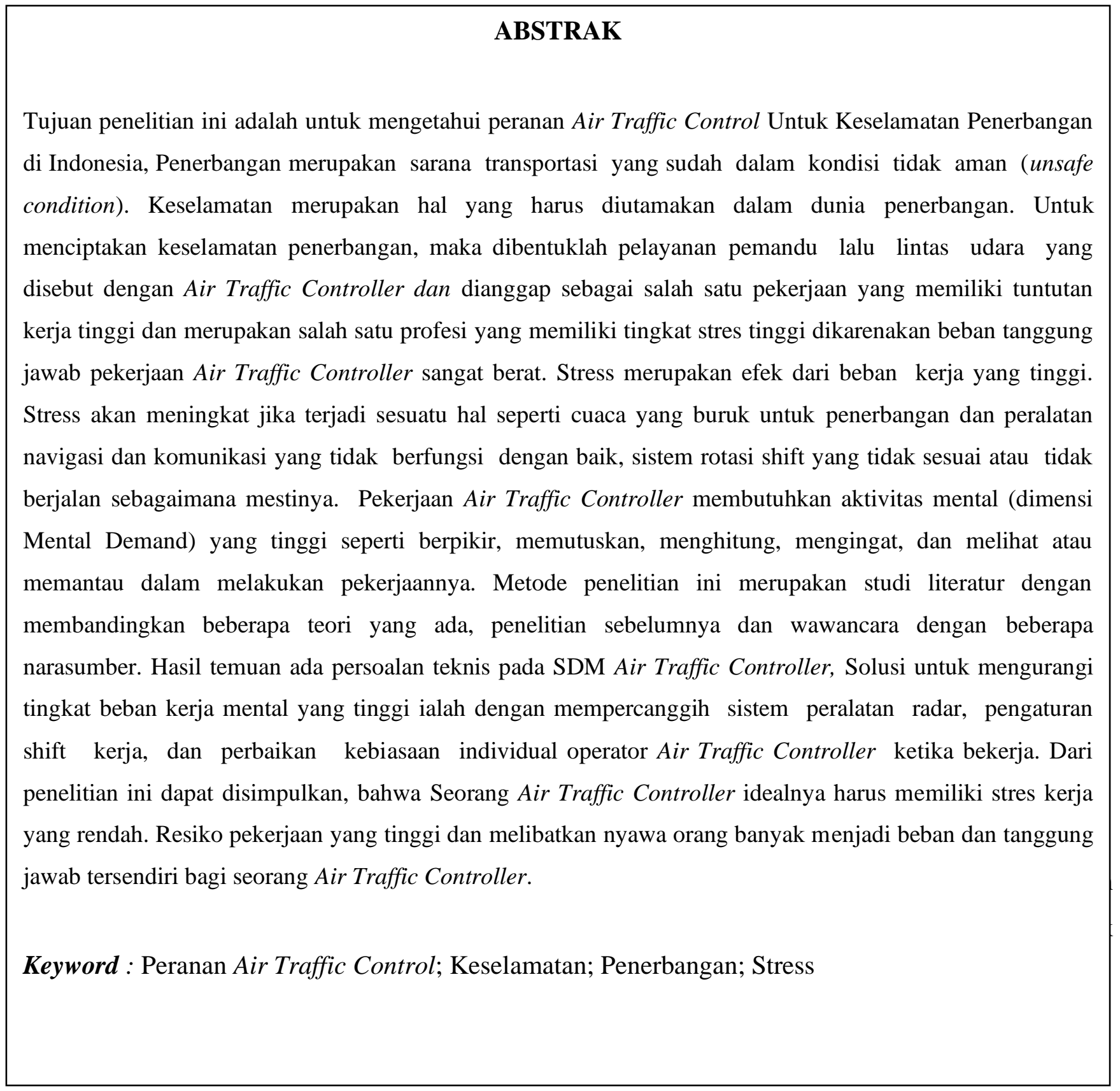




\section{PENDAHULUAN}

Transportasi merupakan salah satu sektor yang mempunyai peran vital dalam merekatkan kesatuan wilayah Negara Kesatuan Republik Indonesia berfungsi untuk distribusi pemerataan pembangunan maupun kesejahteraan bagi warga negaranya. Oleh karena itu, pemerintah secara terus menerus berupaya memperbaiki pelayanan transportasi ke seluruh penjuru tanah air. Transportasi tidak hanya memfasilitasi pergerakan orang/ penumpang, tetapi juga pergerakan barang. Disamping itu, transportasi akan memberikan manfaat untuk menjaga stabilitas harga barang, meningkatkan nilai ekonomi suatu wilayah, dan mempercepat perkembangan wilayah. Pemerintah terus berusaha memberikan pelayanan transportasi yang handal untuk dapat mencapai manfaat yang diharapkan tersebut.

\section{Semakin tingginya frekuensi} penerbangan yang melintasi ataupun mendarat di bandara saat ini, maka tugas dan tanggung jawab pelayanan operasi lalu lintas penerbangan menjadi semakin berat. Oleh karena itu, kualitas dan kehandalan perangkat kerja dan Sumber Daya Manusia yang ada dibelakangnya harus benar-benar prima untuk mencapai keselamatan penerbangan Dalam dunia penerbangan, ada tiga pilar penting yang menjadi faktor utama. Airline, Airport, dan Air Trafic Services (ATS). Yang perlu dibahas adalah mengenai ATS.
Pelayanan yang disediakan ATS antara lain, Flight Information Service, Alerting Service, Air Traffic Advisory Service, dan yang sedang hangat dibicarakan, Air Traffic Control (ATC) Service. Transportasi udara yang ada saat ini membutuhkan sektor pendukung baik dari sisi fasilitas dan sumber daya manusianya. Salah satu sumber daya manusia yang harus hadir dalam menunjang transportasi udara adalah Air Traffic Controller atau dalam bahasa Indonesia lebih dikenal dengan Pemandu Lalu Lintas Udara.

Seorang Air Traffic Controller harus menjalani pendidikan khusus dan seleksi yang ketat. Ketatnya kriteria untuk menjadi seorang Air Traffic Controller disebabkan tugas dan tanggung jawabnya yang sangat penting dalam mengatur ruang lalu lintas udara. Sedikit kesalahan dari Air Traffic Controller dalam mengatur lalu lintas udara bisa menyebabkan akibat yang fatal yaitu kecelakaan. Tugas Air Traffic Controller secara umum bertugas untuk mengatur pergerakan lalu lintas pesawat, Air Traffic Control merupakan pemandu lalu lintas udara yang menjadi rekan terdekat penerbang. Hasil temuan Mosier et al., (2013). menjelaskan bahwa jenis konflik, konteks operasional, fase penerbangan, keadaan operator, dan situasi yang kondusif untuk konflik komunikasi, perbedaan persepsi risiko, dan strategi penyelesaian yang tidak sesuai. 
Penelitian ini dilakukan di Air Traffic Controller salah satu Bandara yang sudah menjadi bandara berskala Internasional yang membuat terjadinya kompleksitas lalu lintas udara baik dari dalam negeri maupun dari luar negeri sehingga tugas bagian Air Traffic Controller menjadi sangat sibuk. Operator Air Traffic Controller diharuskan mempunyai kecepatan dan ketepatan untuk mengolah informasi yang diperoleh dalam membuat keputusan yang tepat agar tidak terjadi kecelakaan. Perhatian perlu juga diberikan pada efisiensi relatif dari berbagai jenis penyedia layanan navigasi udara dan implikasi struktur keuangan (Button \& Neiva, 2014).

Di Indonesia para Air Traffic Controller bekerja di bawah Perum LPPNPI atau yang lebih dikenal dengan AirNav. AirNav adalah salah satu BUMN yang dibentuk khusus oleh Kementrian Perhubungan untuk bertanggung jawab terhadap kelancaran lalu lintas udara di Indonesia. Saat ini pesawat yang terbang dan melewati ruang udara Indonesia dikatan terlalu padat, Kepadatan yang terjadi saat ini menuntut kerja para Air Traffic Controller lebih waspada dan fokus dengan kondisi pekerjaan. Semakin padatnya lalu lintas udara dan terbatasnya jumlah Air Traffic Controller yang ada saat ini membuat banyak para Air Traffic Controller yang mengalami tekanan dan dapat menyebabkan stres saat bekerja maupun setelah selesai melakukan aktifitas pekerjaannya.

Menjadi Air Traffic Controller tidak mudah karena harus melalui pendidikan khusus yang ketat. Ketatnya pendidikan Air Traffic Controller ditujukan untuk menciptakan sumber daya manusia yang berkompeten dan disiplin dalam bekerja. Seorang Air Traffic Controller harus disiplin dan memiliki fokus yang baik. Air Traffic Controller bekerja dengan cara berkomunikasi melalui jaringan komunikasi khusus dibantu dengan sistem instrumen yang ada di ruang kerja. Instrumen yang membantu kerja Air Traffic Controller merupakan alat-alat yang digunakan untuk mengetahui koordinat pesawat, arah angin, pergerakan pesawat dan informasi cuaca. Keadaan lalu lintas udara di Indonesia sendiri yang padat dan sistem radar yang ada juga dapat dikatakan sudah tertinggal dan sering mengalami kerusakan. Sistem radar yang dimiliki saat ini juga sudah tertinggal dengan negara tetangga seperti Singapura dan Malaysia. Insiden yang hampir terjadi salah satunya adalah pada saat radar Bandara Soekarno Hatta yang sempat mati membuat pesawat Lion Air hampir bertabrakan di udara. Kondisi tersebut dapat menjadi potensi stres kerja dan menambah tingkat kesulitas tugas bagi seorang Air Traffic Controller karena harus memandu dengan peralatan seadanya, dimana 
sewaktu waktu dapat menjadi ancaman dan mengakibatkan kejadian fatal.

\section{LANDASAN TEORI}

Sistem otomasi ATC (Air Traffic Control) adalah sistem yang kompleks, yang membantu menjaga ketertiban lalu lintas udara, menjamin interval penerbangan, dan mencegah tabrakan pesawat (Li, et al., 2017). Sesuai dengan kemajuan teknologi, ada beberapa orang yang mendefinisikan mengenai hukum udara, bahwa hukum udara adalah serangkaian ketentuan nasional dan internasional mengenai pesawat, navigasi udara, pengangkutan udara komersial dan semua hubungan hukum publik ataupun perdata, yang timbul dari navigasi udara domestik dan internasional. Untuk melaksanakan tugas tersebut diperlukan seorang petugas ATC dalam pengaturan arus lalu lintas udara yang dimulai dari pesawat melakukan kontak (komunikasi) pertama kali sampai dengan pesawat tersebut mendarat (landing) di bandara tujuan (Susetyadi \& Nurhayati, 2012) Disamping itu diperlukan dukungan prasarana, sarana, serta perangkat peraturan yang sesuai dengan ketentuan- ketentuan yang dikeluarkan ICAO (International Civil Aviation Organization) Organisasi Penerbangan Sipil Intemasional, yang dari hari ke hari terus dilakukan amandemen sesuai dengan pengembangan arus lalu lintas penerbangan dan teknologi. guna mendukung kelancaran pelayanan lalu lintas penerbangan, pada setiap pesawat udara dan bandar udara yang beroperasi harus dilengkapi dengan fasilitas komunikasi yang memadai. Fasilitas komunikasi penerbangan tersebut digunakan untuk komunikasi antara pengatur lalu lintas udara dengan pilot / pesawat dan antara petugas lalu lintas udara dengan unit lain di bandar udara tersebut maupun dengan petugas Pengatur Lalu Lintas Udara di bandar udara lainnya.

Pelayanan yang diberikan oleh petugas pemandu lalu lintas udara terdiri dari tiga pelayanan, yaitu : 1. Pelayanan Lalu Lintas Udara Terkontrol (Air Traffic Control Service), terbagi menjadi tiga bagian yaitu : a. Area Control Service Pelayanan yang diberikan kepada penerbang yang sudah menjelajah (enroute flight) terutama yang termasuk penerbangan terkontrol (controlled flights). Unit yang memberikan pelayanan ini disebut Area Control Centre (ACC). b. Approach control service Pelayanan yang diberikan kepada pesawat yang berada di ruang udara sekitar bandara baik yang sedang melakukan pendekatan maupun yang baru berangkat, terutama bagi penerbangan yang beroperasi terbang instrumen yaitu penerbangan yang mengikuti aturan penerbangan instrumen atau dikenal dengan Instrument Flight Rule (IFR). Unit yang memberikan pelayanan ini disebut 
Approach Control Office (APP). c. Aerodrome

Control Service Pelayanan yang diberikan kepada pesawat yang berada di bandara dan sekitarnya (vicinity of aerodrome), yang dilakukan di menara pengawas (Control Tower). Unit yang memberikan pelayanan ini disebut Aerodrome Control Tower (ADC).

Setiap bandar udara memiliki bangunan Air Traffic Control (ATC) berperan penting sebagai pusat koordinasi untuk keselamatan dan efisiensi pergerakan pesawat terbang (Pariyan, Gunawan, \& Fahriani, 2018) Bangunan ATC atau menara pengawas merupakan sebuah bangunan permanen yang berfungsi memantau area-area di dalam dan sekitar bandar udara yang ditentukan untuk diawasi sehingga dapat di lakukan pengawasan untuk menjaga keselamatan penerbangan. Menara pengawas merupakan bangunan tertinggi yang berada di sekitar kawasan bandar udara.

\section{Air Traffic Controller (ATC) adalah} penyedia layanan yang mengatur lalu-lintas di udara terutama pesawat terbang untuk mencegah pesawat terlalu dekat satu sama lain dan tabrakan (Prasetyo \& Budiawan, 2019). ATC merupakan pengatur lalu lintas udara yang tugas utamanya mencegah pesawat terlalu dekat satu sama lain dan menghindarkan dari tabrakan (making separation). Selain tugas separation, ATC juga bertugas mengatur kelancaran arus traffic (traffic flow), membantu pilot dalam menghandle emergency/darurat, dan memberikan informasi yang dibutuhkan pilot (weather information atau informasi cuaca, traffic information, navigation information, dll). Selain tugas-tugas ATC yang mempunyai tanggung jawab yang besar, ATC juga mempunyai batas kendali, yaitu kendali darat dan kendali udara. Wilayah kendali darat mencakup seluruh pergerakan di dalam airside Airport. Pengendalian dalam wilayah udara mencakup arrivals, instrument approach, visual approach, take off, landing, dan transisi kontrol dari sebuah aerodrome ke aerodrome lain.

Selain wilayah kendali yang begitu luas, ATC juga dituntut untuk dapat menjalankan peraturan yang disediakan sesuai dengan tujuan pelayanan lalu-lintas udara. Tetapi disinyalir karena adanya tingkat stress kerja yang tinggi pada ATC, sehingga mengakibatkan beberapa kesalahan yang dapat mengakibatkan insiden. Peneliti lainnya menambahan, untuk mencegah tabrakan antar pesawat, mencegah tabarakan pesawat dengan obstructions, mengatur arus lintas udara yang aman, cepat dan teratur kepada pesawat udara, baik yang berada di ground atau yang sedang terbang/melintas dengan menggunakan jalur yang telah ditentukan (Ricardianto \& An, 2015) Dalam pelaksanaan tugas tersebut diperlukan seorang petugas ATC dalam pengaturan arus lalu lintas udara yang dimulai dari pesawat melakukan komunikasi 
(contact) pertama kali sampai dengan pesawat tersebut mendarat (landing) di Bandar udara tujuan. Umumnya skema pemodelan ATC yang diperkenalkan membuatnya menjadi alat umum yang fleksibel untuk mensimulasikan dan mengendalikan sistem Transportasi Udara dalam skenario realistis (Monechi, Servedio, \& Loreto, 2015).

\section{METODE PENELITIAN}

Metode penelitian ini merupakan studi literatur dengan membandingkan beberapa teori yang ada, penelitian sebelumnya dan wawancara dengan beberapa narasumber. Untuk memperoleh informasi dan data yang diperlukan dalam penulisan ini maka digunakan tehnik pengumpulan data sebagai berikut dokumen/kepustakaan, yaitu teknik memperoleh data dengan mempelajari dokumen-dokumen yang berhubungan dengan permasalahan yang diteliti. Teknik analisis data dalam penelitian ini menggunakan metode analisis secara kualitatif dengan pola berfikir induktif. Proses analisis tersebut dilakukan dengan teknik analisis data yang bersifat content analisis yaitu melalui tahap pendiskripsian secara rinci, sifat, ciri dan substansi data serta konteksnya, kemudian secara teoritik interpretatif dan menggunakan logika induksi kemudian ditarik suatu kesimpulan.

\section{PEMBAHASAN}

Pemandu Lalu Lintas Udara (Air Traffic Controller, ATC) adalah profesi yang memberikan layanan pengaturan lalu lintas di udara terutama pesawat udara untuk mencegah antarpesawat terlalu dekat satu sama lain, mencegah tabrakan antar pesawat udara dan pesawat udara dengan rintangan yang ada di sekitarnya selama beroperasi. ATC atau yang disebut dengan Air Traffic Controller juga berperan dalam pengaturan kelancaran arus lalu lintas, membantu pilot dalam mengendalikan keadaan darurat, memberikan informasi yang dibutuhkan pilot (seperti informasi cuaca, informasi navigasi penerbangan, dan informasi lalu lintas udara). ATC adalah rekan terdekat pilot selama di udara, peran ATC sangat besar dalam tercapainya tujuan penerbangan. Semua aktivitas pesawat di dalam Manuvering Area diharuskan mendapat mandat terlebih dahulu dari ATC, yang kemudian ATC akan memberikan informasi, instruksi, clearance / mandat kepada pilot sehingga tercapai tujuan keselamatan penerbangan, semua komunikasi itu dilakukan dengan peralatan yang sesuai dan memenuhi aturan. ATC merupakan salah satu media strategis untuk menjaga kedaulatan suatu wilayah/suatu negara. 
ATC melakukan pengaturan lalu lintas udara di menara / tower untuk Aerodrome Control Tower, agar dapat melihat dengan jelas keadaan runway / Landas pacu, sedangkan untuk Approach Control Unit dan Area Control Centre berada di ruangan yang letaknya berdekatan dengan menara / tower untuk memudahkan koordinasi. Namun tidak semua bandar udara menerapkan kondisi demikian, disesuaikan dengan kondisi lalu lintas udara dan kepadatannya. Sesuai dengan tujuan pemberian Air Traffic Services, Annex 11, International Civil Aviation Organization (ICAO), 1998, Pelayanan Pengendalian Lalu Lintas Udara (Air traffic control service), pada ruang udara terkontrol / Controlled Airspace terbagi menjadi tiga bagian yaitu:

1. Aerodrome Control Service Memberikan layanan Air Traffic Control Service.

2. Flight Information Service.

3. Alerting Service yang diperuntukkan bagi pesawat terbang yang beroperasi atau berada di bandar udara dan sekitarnya (vicinity of aerodrome) seperti take off, landing, taxiing, dan yang berada di kawasan manuvering area, yang dilakukan di menara pengawas (control tower). Unit yang bertanggung jawab memberikan pelayanan ini disebut Aerodrome Control Tower (ADC).

Approach Control Service memberikan layanan Air Traffic Control Service, Flight Information Service, dan Alerting Service, yang diberikan kepada pesawat yang berada di ruang udara sekitar bandar udara, baik yang sedang melakukan pendekatan maupun yang baru berangkat, terutama bagi penerbangan yang beroperasi terbang instrumen yaitu suatu penerbangan yang mengikuti aturan penerbangan instrumen atau dikenal dengan Instrument Flight Rule (IFR). Unit yang bertanggung jawab memberikan pelayanan ini disebut Approach Control Office (APP). Area Control Service Memberikan layanan Air Traffic Control Service, Flight Information Service, dan Alerting Service, yang diberikan kepada penerbang yang sedang menjelajah (enroute flight) terutama yang termasuk penerbangan terkontrol (controlled flights). Unit yang bertanggung jawab memberikan pelayanan ini disebut Area Control Centre (ACC).

Pelayanan Informasi Penerbangan (Flight Information Service) Flight Information Service adalah pelayanan yang dilakukan dengan memberikan berita dan informasi yang berguna dan bermanfaat untuk keselamatan, keamanan, dan efisiensi bagi penerbangan. Pelayanan keadaan darurat (alerting service) 
Pelayanan keadaan darurat adalah pelayanan yang dilakukan dengan memberitahukan instansi terkait yang tepat, mengenai pesawat udara yang membutuhkan pertolongan search and rescue unit dan membantu instansi tersebut, apabila diperlukan. Beban kerja dalam ATC pun sangat patut diperhitungkan, Disiplin dan tanggung jawab yang tinggi, jam kerja di ATC diatur secara bergiliran berdasarkan "position log" atau "shift".

Pada Aerodrome Control Tower, bidang pekerjaannya yang dibagi dalam beberapa unit, di antaranya Clearance Delivery, unit yang memberi informasi semua Rute Pelayanan Lalu Lintas Udara/ ATS Route, ketinggian pesawat yang diminta atau diizinkan untuk terbang ke tujuan. Ground Control, mengatur semua pergerakan mulai pesawat itu push back, sampai pesawat ke taxiway, menanti di ujung landas pacu untuk lepas landas. Assistant Tower Controller, tugasnya membantu aktivitas tower controller. Tower Controller sendiri mengatur lepas landas dan mendaratnya pesawat. Sekalipun jam kerja sudah diatur, setiap rutinitas pasti ada kejenuhannya. Namun karena pekerjaan yang mempertaruhkan nyawa penumpang pesawat, dengan fokus dan tanggung jawab profesi, ATC diharuskan untuk tidak merasakan kejenuhan ketika bekerja.

Pada hal ini Penyedia layanan pemanduan lalu lintas udara wajib menerapkan pola manajemen stress pada beban kerja ATC dan manajemen keselamatan. Menurut Dokumen 9426 Air Trafic Planning Manual, pemimpin unit pemandu lalu lintas udara (unit chief controllers) dan para petugas evaluasi (evaluation officers) perlu selalu waspada atas tanda-tanda stres pada anggota stafnya dan mestinya tidak ragu-ragu untuk membantu meringankannya. Pada langkah ini, suatu diskusi informal supervisor dengan pegawai pelaksana sering dapat menghindari hilangnya kecakapan secara progresif. Ini dapat juga meningkatkan keselamatan operasi unit yang terkait. Di Indonesia sendiri, pemandu lalu lintas udara akan diberikan lisensi atau sertifikat kecakapan apabila berusia sekurang-kurangnya 21 tahun, lulus pemeriksaan kesehatan sekurang-kurangnya level 3, lulus pelatihan yang tidak kurang dari 3 bulan di tempat yang diakui secara hukum dan telah menguasai beberapa pengetahuan berikut ini selama menempuh pendidikan dan pelatihan. Sertifikat Kecakapan tersebut akan diberikan oleh Direktorat Jenderal Perhubungan Udara, setelah memenuhi persyaratan-persyaratan yang ditentukan sesuai dengan Peraturan Keselamatan Penerbangan Sipil bagian 69

\section{HASIL TEMUAN}

Seorang Air Traffic Controller harus menjalani pendidikan khusus dan seleksi yang ketat. Ketatnya kriteria untuk menjadi seorang 
Air Traffic Controller disebabkan tugas dan tanggung jawabnya yang sangat penting dalam mengatur ruang lalu lintas udara. Sedikit kesalahan dari Air Traffic Controller dalam mengatur lalu lintas udara bisa menyebabkan akibat yang fatal yaitu kecelakaan. Salah satu kecelakaan pesawat yang melibatkan Air Traffic Controller terjadi pada penerbangan. Penelitian ini turut mendukung beberapa penelitian sebelumnya mengenai ATC di bandara di Indonesia, yang dilakukan oleh (Susanti, 2013, Budiman, Pujangkoro, \& Anizar, 2013; Susanti; 2017; Fathimahhayati, 2018). Penelitian ini juga mendukung laporan dan beberapa penelitian sebelumnya mengenai pengembangan, organisasi, inovasi pada ATC di bandara asing (Poole Jr, 2013; Adler, Hanany, \& Proost, 2014; Spinardi, 2015; Petersen, 2018).

\section{KESIMPULAN}

Peristiwa kecelakaan pesawat merupakan peringatan bagi petugas pengawas lalu lintas udara atau Air Traffic Control dan para pilot perusahaan penerbangan nasional maupun internasional agar lebih berhati-hati terhadap semua kemungkinan/halangan yang membahayakan keselamatan penerbangan mulai dari persiapan penerbangan, lepas landas, sampai pada setelah melaksanakan penerbangan hingga mendarat, kewaspadaan tersebut harus diperhatikan demi keselamatan penerbangan. Tidak semua kecelakaan yang terjadi disebabkan karena kesalahan dari pihak pengatur lalu lintas udara saja, tetapi ada pihak lain yang dapat mengakibatkan kecelakaan pesawat udara, misalnya: penumpang, pilot, perusahaan penerbangan, petugas navigasi dan lain-lainnya yang dengan sendirinya harus ada pihak yang bertanggung jawab untuk keselamatan penerbangan tersebut. Dalam Peraturan Pemerintah ini sebagai peraturan pelaksana dari Undang-Undang Penerbangan memberikan sanksi berupa sanksi administrasi kepada personil atau petugas ATC yang apabila dalam menjalankan tugasnya telah melakukan kelalaian sehingga menyebabkan terjadinya kecelakaan pesawat. Sanksi administrasi dapat berupa pemberian peringatan, pemberhentian sementara dari tugasnya, atau pencabutan sertifikat kecakapan.

Tanggung jawab utama yang dimiliki oleh seorang ATC adalah menjamin keselamatan pesawat berserta seluruh awak dan penumpang pesawat. Banyaknya tuntutan pekerjaan, membuat seorang ATC harus mampu untuk menyesuaikan diri, jika hal tersebut tidak berhasil dilakukan maka akan menimbulkan ketidakseimbangan yang merupakan salah satu penyebab timbulnya stress kerja. Apabila individu kurang mampu untuk mengadaptasikan dirinya dengan tuntutan - tuntutan atau masalah - masalah yang muncul, maka individu tersebut akan cenderung mengalami stress. Stress kerja 
dapat menimbulkan berbagai konsekuensi pada individu yang bekerja, baik secara fisiologis, psikologis, maupun perilaku.

\section{DAFTAR PUSTAKA}

Adler, N., Hanany, E., \& Proost, S. (2014). Managing European air traffic control provision. In Managing European air traffic control provision. Fourth SESAR Innovation Days, 25th-27th November.

Budiman, J., Pujangkoro, S., \& Anizar. (2013). Analisis Beban Kerja Operator Air Traffic Control Bandara Xyz Dengan Menggunakan Metode Nasa-Tlx. Jurnal Teknik Industri USU.

Button, K., \& Neiva, R. (2014). Economic efficiency of European air traffic control systems. Journal of Transport Economics and Policy (JTEP). Journal of Transport Economics and Policy (JTEP), 48(1), 6580.

Fathimahhayati, L. D. (2018). Analisis Beban Kerja Mental Pada Operator Air Traffic Controller (ATC) Dengan Metode Subjektif dan Objektif (Studi Kasus: Airnav Bandar Udara XYZ). Jurnal Ilmiah Bidang Teknologi, 10 (1), 69-76.

Li, R., Zhou, Z., Cheng, Y., \& Wang, J. (2017). Failure Effects Evaluation for ATC Automation $\quad$ System. Applied
Computational Intelligence and Soft Computing.

Monechi, B., Servedio, V. D., \& Loreto, V. (2015). Congestion transition in air traffic networks. PloS One, 10(5), e0125546.

Mosier, K. L., Rettenmaier, P., McDearmid, M., Wilson, J., Mak, S., Raj, L., \& Orasanu, J. (2013). Pilot-ATC communication conflicts: Implications for NextGen. The International Journal of Aviation Psychology. The International Journal of Aviation Psychology, 23(3), 213-226.

Pariyan, V., Gunawan, I., \& Fahriani, F. (2018). Analisis ulang struktur bangunan Air Traffic Control (ATC) di Bandara Depati Amir Pangkalpinang. FROPIL (Forum Profesional Teknik Sipil), 6, 113-125.

Petersen, R. (2018). Capacity Constraints for Air Traffic Flow Development. Linköping University. Linköping University, The Institute of Technology.

Poole Jr, R. W. (2013). Organization and innovation in air traffic control.

Prasetyo, A. D., \& Budiawan, W. (2019). Studi Stres Kerja Operator Air Traffic Control (ATC) Pada Bandara Ahmad Yani Semarang. Industrial Engineering Online Journal, 7(4).

Ricardianto, R. P., \& An, C. (2015). Menara Air Traffic Control (ATC) Terbaik Pada Bandar Udaa Di Kawasan Eropa - Afrika. 


\section{Manajemen Bisnis Transportasi Dan}

Logistik, 2(1), 23-43.

Spinardi, G. (2015). Up in the air: barriers to greener air traffic control and infrastructure lock-in in a complex socio-technical system. Energy Research \& Social Science, $6,41-49$.

Susanti, S. (2013). Analisis Kebutuhan Personel Air Traffic Controller (ATC) Di Pusat Pengendalian Lalu Lintas Penerbangan Makassar. Warta Penelitian Perhubungan, 25(2), 119-128.

Susanti, S. (2017). Faktor Penyebab Kelelahan dan Stres Kerja Terhadap Personel Air Traffic Controller (ATC) di Bandar Udara "X”. Warta Ardhia, 42(3), 139-148.

Susetyadi, A., \& Nurhayati, Y. (2012). Kebutuhan Personel Air Traffic Controller (ATC) Di Bandara Sultan Mahmud Badaruddin II Palembang. Warta Penelitian Perhubungan, 24(5), 474-485. 